\title{
Modern IP Offences and the Medical Profession
}

ISSN: 2578-0379

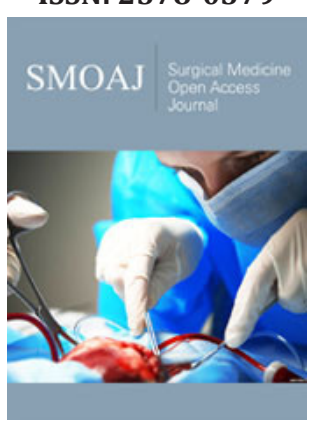

*Corresponding author: Simon Raymond, Consultant specializing in Medical and Scientific Research, Alumnus, Australia

Submission: 侮 May 30, 2019

Published: 笽June 13,2019

Volume 2 - Issue 4

How to cite this article: Simon Raymond. Modern Medicine and Surgery: Physics and War. Surg Med Open Acc J.2(4). SMOAJ.000545.2019. DOI: 10.31031/SMOAJ.2019.02.000545.

Copyright@ Simon Raymond, This article is distributed under the terms of the Creative Commons Attribution 4.0 International License, which permits unrestricted use and redistribution provided that the original author and source are credited.

\section{Simon Raymond*}

Consultant specializing in Medical and Scientific Research, Australia

\begin{abstract}
IP offences have been recognized as perhaps the most important of offences in modern society. Current laws are able to deal with offences relating to plagiarism, copyright, and theft of IP from computer and related devices. It seems logical that theft of IP directly from the mind of individuals (For instance, copying directly from neurological processes) is the next step in IP offences that should be described and
\end{abstract} researched.

Keywords: Copyright; Plagiarism; IP offences; Intellectual property

\section{Introduction}

It seems reasonable to suggest that of the modern offences sciences is beginning to understand and able to describe, IP offences are prominent. Copying the intellectual property of others has always been an offence viewed as significant stemming back to more basic types surrounding plagiarism and copyright offences.

At present there appears to be mined abuse related programs as a focus and this may include copying IP directly from the mind and neurological processes of another. Obviously electronic and IP crimes in terms of copying from the computer related devices of another is already understood to some extent. However, copying from directly from the mind of another is not yet well understood and the following publication describes this in addition to the possibility that the medical profession may be of use in terms of investigations surrounding such modern IP offences that may be occurring.

The publication follows in the manner described [1-13]:

A. That mind abuse programs may be occurring even in countries usually known for having a focus on proper following of rules

B. Research shows an axis of interest directed at the mind of individuals in which copying of neurological processes may be occurring

C. Formulation and Summary of the Findings

\section{Mind Abuse Related Programs}

The following has been accepted for presentation at: $7^{\text {th }}$ International Conference on General Surgery and Surgical Research Oct 23-24, 2019, Rome, Italy. The war climate globally is now stated as, in recent years and ongoing, consisting of not only terrorist type warfare but also official world war type climate, after systematic analysis according to key criteria for assessment of combat type. The key features present, according to generally accepted criteria, with regards to combat considered characteristic of world war type climate (categorization):

A. Pledges to a leader positioning themselves in a defined manner

B. Mind abuse type programs (mind coding and other)

*Mind abuse programs are carried out for numerous reasons (for example, to achieve robotic following of the given leadership through brainwashing and related abuse)

USA, Britain and others have contained, although perhaps transiently, markers indicating such climate to have been present in such areas. See [1] below. Given the markers, programs 
run during the years 2009-2016 (in addition to any other periods relevant) should be checked for mind abuse type programs. This would include:

\section{A. Brain Initiative program;}

B. Mind Mapping program, of which both are indexed on NLM, USA National Library of Medicine. An Australian neurosurgeon was involved in the above with the given government members' the programs may be of value but should be checked appropriately. In addition, consideration given to plans for protocol to check other programs if appropriate.

\section{Conclusion}

The typical aspects of world war climate have been detailed along with the reasoning behind such regimes and groups containing such programs including mind abuse directed activities. Furthermore, it is advised that the programs including those detailed are checked to ensure they provide quality medical information for the intended use of the indexing services.

\section{Axis of Focus}

There is currently a context of world war type climate in addition to crises internationally regarding infectious diseases. This has, as adjoined, the developing evidence of the awareness of infectious agents [1 -13]. Although infectious agents may not be aware in the same way as macro-being, there is still sensitivities given the world war type climate as discussed in Example 1. This means that in addition to ensure antimicrobials only be used on micro-organisms there is also interest in research to ensure that micro-organism awareness isn't the same as macro being and war (or, other) type harshness occurring to such lifeforms. Respect for biology remains important. Extending on the above, the awareness of infective agents should be taken seriously $[3,13]$ :

A. There is consideration by respected universities regarding awareness of computers and the need to consider whether computers should be provided similar rights to that of human rights.

B. There is merger occurring with the IT industry. Examples include three-dimensional printing of biology.

C. There is support for the opinion that infective agents may contain awareness, and this is detailed in previous publications. It is supported further in this publication by the ability of infective agents to sense surroundings in the contexts of discriminating between self and foreign.

On the other hand, the seriousness of the invasion of the person of the being by micro-organisms must be taken into account. In addition to whether there is any awareness in the intent by the micro-organisms. The evidence in recent research by the current author is as follows: At present, there is demonstration of the following:
A. Microorganisms in the CNS performing voltage gated ion channel communications, possibly demonstrating consciousness or at least a level of awareness.

B. An Axis that appears potentially to have been formed (at least in part) by microorganisms from the intestine(s) through to the pituitary gland (gut-brain axis), and notably the pituitary gland is an area around which used to be termed historically as the seat of the soul, or mind. Based on the above, it could be viewed that these two signs (indications) demonstrate the attempted invasion of the mind of the person by another entity, for instance that of the infective microorganisms. The implication of microorganisms in mental illness has been delineated previously by the current author (researcher) in reports listed below in the section titled References. It is worth considering whether a level of total (or, near total) control could be gained by the microorganisms, causing mental illness at the level of psychosis or insanity. The above is worth further investigating.

Future research will look at whether the micro-organisms could also be copying neurological process and whether that is a form of IP theft $[2-3,13]$. There is already evidence that neurological type processes are copied by the axis of focus and the mimicking of such processes achieved $[3,13]$. Protection of clinical doctors in terms of utilization of antimicrobials is discussed in other publications and conference proceedings. The important point in the current publication surrounds the evidence above that the Axis of focus may be involved in the copying of IP (or, neurological processes) from the mind of individuals.

\section{Formulation and Summary}

IP offences have been recognised as perhaps the most important of offences in modern society. Discussion of the above points highlights an Axis of interest directed toward the mind of individuals which includes copying and mimicking of mind (neurological) processes.

Future lectures will look at the progression of this topic. For instance, whether this can already commence being included in science type degrees. An example of an exam type question as follows:

\section{Symptoms and disturbances of a person suffering attempts at modern IP theft directly from the mind of the individual (or, copying neurology) includes:}
A. Cortical spreading depression
B. Invasion type hallucinations (E.g. Nazis or foreigners)
C. Migraine and Aura
D. All of the above
E. Other

Further to this, research and development in the field would include development of scans and other investigations. Clinical note taking methodology, obviously (from the above) also important. 


\section{References}

1. Raymond S (2019) Site attachment inhibition therapeutics: Ethical considerations Part 2, Euro scion conference on cancer stem cell \& oncology research: Advancement in cancer research prospects of new therapeutic strategies, Seoul, South Korea.

2. Raymond S (2018) Research update on modern medicine and surgery. Molecular Biology Mol Biol 7(3): 1-3.

3. Raymond S (2018) Site attachment inhibition and the application of quantum physics to medicine and surgery. J Human Soc Sci (IOSR-JHSS) 23(1): 8-12.

4. Raymond S (2018) Site attachment inhibition therapeutics: A new mode of action pathway in antimicrobial therapy. International Journal of Engineering Research and Development (IJERD) 14(1): 75-78.

5. Raymond S (2016) $6^{\text {th }}$ International conference and expo on immunology (870 ${ }^{\text {th }}$ Congress) Chicago, USA.

6. Raymond S (2017) Annual conference on microbial pathogenesis, infectious disease, antimicrobials and drug resistance, Toronto, Canada.

7. Raymond S (2016) Development of new strategic pathways for antiviral therapy. J Clin Cell Immunol 7: 5(Suppl).
8. Raymond S (2016) Consciousness and the development of new strategic pathways for antiviral therapy a focused analysis on HIV. International Journal of Sciences: Basic and Applied Research (IJSBAR) 29: 146-154.

9. Raymond S (2016) The development of new antimicrobial pathways combatting the threat of antimicrobial resistance. International Journal of Sciences: Basic and Applied Research (IJSBAR) 30: 22-28.

10. Raymond S (2017) Site attachment inhibition therapeutics: A core summary. Journal of Aids \& Clinical Research 8 (2): 1-3.

11. Raymond S (2018) $12^{\text {th }}$ World congress on pharmaceutical sciences and pharma industries, site attachment inhibition therapeutics: Dealing with association versus causation issues, London, UK.

12. Raymond S (2018) $10^{\text {th }}$ International conference on clinical and cellular immunology, site attachment inhibition therapeutics: Dealing with association versus causation issues, Madrid, Spain.

13. Raymond S (2017) The Role of infectious disease and inflammation in psychiatric illness. Imperial Journal of Interdisciplinary Research 3(1): 510-513. 